\title{
Study on learning acrobatic elements with groups of girls using programmed instruction in gymnasium
}

\author{
Talaghir Laurentiu - Gabriel ${ }^{1 a}$, Bădău Dana² \\ ${ }^{1}$ University "Dunarea de Jos", Domneasca street no.46, Galati, 800008, Romania \\ ${ }^{2}$ University of Medicine and Pharmacy, Gh. Marinescu street no.38, Tîrgu Mures, 540061, Romania
}

\begin{abstract}
This paper presents a part of an extensive research which was conducted with students of class VI in secondary school. In this research were developed several learning strategies with acrobatic elements that are specified in the curriculum for this age level. The paper aims to outline the results achieved in the experiment groups of girls. Also, the paper presents the model proposed for the realization of teaching strategies based on programmed instruction method. Three of acrobatic elements whom were applied these teaching strategies were common elements (performed by girls and boys) and one had a character specific to girls. Through the results obtained we can say that the effectiveness of applied strategies was proved by practice, thus achieving the learning unit objectives.
\end{abstract}

Keywords: physical education; acrobatic elements; programmed instruction

\section{Introduction}

Learning efficiency can be defined as an organized management in order to ensure a functional performance of the educational process in the light of the criteria set. This management is based on consideration of regularities and principles of education, current forms and methods, and the peculiarities of the system and the internal and external conditions.

The future of physical education (PE) depends on the quality of emerging committed professionals and their ability to teach across the different activity areas contained within the National Curriculum for physical education, [6].

Efficiency is based on the scientific organization of student work oriented not only to a simple performance, but also to obtain results related to specific conditions, [7].

The methods by which the teacher provides acquiring by students of a system of knowledge, abilities, motor skills and also leading to increase the indices of development in

\footnotetext{
a Corresponding author: gtalaghir@ugal.ro
} 
motor skills, and helping to educate students in the spirit of civic - are called educational methods.

The methods are classified according to several criteria, [2], but regardless of classification, they want to provide easy way to acquire knowledge and skills in various fields.

In education, the working method along with the proposed exercises and material resources lead to achieve a teaching strategy. This notion of pedagogical sciences is used successfully in school physical education.

Gymnastics has a very rich means content, which gives basic discipline status of the system of physical education and sports, having own theory and method of teaching, resources and specific forms of organization, based on data of related sciences (anatomy, physiology, biomechanics, biochemistry, psychology, pedagogy), [4].

Acrobatic gymnastics elements are skills artificially designed in order to create difficulty for increasing general motor skills of the individual. They are considered important for the development of moral character and will. Acrobatic elements are an essential part of the educational process in physical education. These are contained in specialized curriculum throughout schooling.

Implementing the strategy teaching on four acrobatic elements in the sixth grade wanted to contribute to a better assimilation of them, and at the same time to achieve a favorable result in physical education.

\section{Material and methods}

The research hypothesis consists in the fact that the use of programmed instruction as a learning method for acrobatic elements will help quickly and easily acquire them by girls in sixth grade. Application of this method was achieved by developing teaching strategies for each acrobatic element selected.

Subjects: The experiment took place in the Secondary School no. 22 of Galati. In the experiment were included two classes of VI. The control group was composed of 9 girls and experimental group of 15 girls.

Research methods used in the research were: pedagogical experiment which has intervened both on schedule and on planning activity in physical education lessons in class VI; method of experts was applied through three teachers who rated acrobatic elements tested. The evaluation was done by giving notes of each evaluator, the final grade being the average of them; statistical method, in which we used Student Pairs Test and Independent Student Test, conducted by SPSS 2.0; tests method followed testing for selected acrobatic elements of the current curriculum, which have been learned with the girls: rolling back from squat in wide apart, rolling forward from wide apart in squat, bridge up and sitting on hands - rolling.

Procedure: in curriculum of learning units, the acrobatic elements have had assigned a number of 18 classes in the first semester, carried using the methods, means and forms of organization selected within teaching strategy of proposed schedule.

Application of programmed instruction consists from the fragmentation into short elements, accessible (sequences, methodical steps, doses, microstructures) and placing them into order of difficulty, depending on the individual or group, but falling in some limits of time, $[1,3]$.

In learning of acrobatic elements were used the linear programmed instructions. To achieve the proposed strategy were developed specific means of actuation, which were grouped into an exercise program. In practice, female students could not go to the next exercise in the program only under the conditions in which previous exercise was carried 
out in satisfactory technical parameters. Also, previous exercise had to have an appropriate workload indicated in dosage.

From the table we can see easily the content items of the proposed strategy for learning of this acrobatic element. Thus, the number of suggested exercises was five and for each exercise was recommended one dosage that contribute to expected result.

During the practicing, after a first action of the students, the teacher intervened with corrective instructions for actions performed deficient. In this way, over the next executions, they are improving in terms of technique execution.

Table 1 - Didactic model for acrobatic element "rolling back from squat in wide apart.

\begin{tabular}{|c|c|c|}
\hline & Exercise program (Means) & Dosage \\
\hline \multicolumn{2}{|c|}{$\begin{array}{l}\text { Exercise } 1 \text { - Sitting squat, rolling back with bent arms lifting up and laying on the } \\
\text { ground at the head and returning. }\end{array}$} & 3 series $x 5$ reps \\
\hline \multicolumn{2}{|c|}{$\begin{array}{l}\text { Exercise } 2 \text { - Sitting wide apart, rolling back with lifting arms bent up and laying palms } \\
\text { on the ground at the head and returning. }\end{array}$} & 3 series $x 5$ reps \\
\hline \multicolumn{2}{|c|}{$\begin{array}{l}\text { Exercise } 3 \text { - Sitting squat, rolling back with palms on the ground and stretching the } \\
\text { legs in wide apart and returning. }\end{array}$} & 3 series $\mathrm{x} 5$ reps \\
\hline \multicolumn{2}{|c|}{$\begin{array}{l}\text { Exercise } 4 \text { - Sitting squat, rolling back simultaneously with going in wide apart, } \\
\text { supporting soles on the ground. }\end{array}$} & 5 reps \\
\hline \multicolumn{2}{|c|}{ Exercise 5 - Sitting squat, aggregate execution with help. } & 5 reps \\
\hline \multicolumn{3}{|c|}{ Strategy teaching - learning - rolling back from squat in wide apart } \\
\hline Methods & Methodical instructions and working groups & Materials \\
\hline $\begin{array}{l}\text { Programmed instruction } \\
\text { Demonstration } \\
\text { Practice } \\
\text { Observation } \\
\text { Correction } \\
\text { Appreciation }\end{array}$ & $\begin{array}{l}2 \text { groups } \\
\text { Individual practice } \\
\text { If performed correctly, go to the next exercise. } \\
\text { Exercise } 1 \text { - Rolling wide until the nape; overturning pelvis } \\
\text { over support. } \\
\text { Exercise } 2 \text { - Unbalancing the torso backward with large } \\
\text { amplitude. } \\
\text { Exercise } 3 \text { - Ground support of soles, as close to the shoulder. } \\
\text { Exercise } 4 \text { - Help is granted from backward. }\end{array}$ & $\begin{array}{l}4 \text { gym } \\
\text { mattresses }\end{array}$ \\
\hline
\end{tabular}

After the exercise was carried out according to the number of repetitions and quality requirements in terms of technical execution, students go to the next exercise, as it found in the proposed program.

The use of programmed instruction as a working method focuses on the qualitative aspect of the training process. At the same time, through appropriate dosage, programmed instruction has positive effects on learning, also due to granting a workload corresponding to the level of preparedness of students for practice. From these perspectives, the use of this method of learning to students, especially the motor skills, specifically on sports disciplines, is favorable premise for achieving superior results.

The most important aspect in the application of this method is to practice each work means in terms of quality. The workload is not a dominant issue in the sense that the student is not allowed to repeat a mistake several times. Completion of the proposed program was mandatory for components of the experimental group.

The same types of teaching strategies were built also for the other acrobatic elements, which are included in the curriculum at this age level. Table 1 summarizes only the synthetic model of developing teaching strategy that is based on programmed instruction method. 


\section{Results and Discussions}

The results recorded were centralized and were subjected to statistical analysis to form an accurate picture of level of the progress achieved and to submit to the rigors of the scientific nature of the research (Table 2).

Statistical interpretation of the results was done in two directions, namely, on the one hand between groups (control and experiment) and on the other hand in the same group between initial and final testing.

The first direction has enabled direct comparison between the two groups. In this way it has been observed if the group that used programmed instruction in practice has recorded superior results compared to the other group or not this happens.

The second direction wanted to provide information on progress made by each group subjected to the study in relation to the operating means independently proposed.

Table 2 - Statistical analysis of the initial and final test between the two groups of girls

\begin{tabular}{|c|c|c|c|c|c|c|}
\hline Tests & $\begin{array}{c}\text { Groups } \\
\text { Girls }\end{array}$ & $\begin{array}{c}\text { Number of } \\
\text { subjects }\end{array}$ & Average & $\begin{array}{r}\text { Standard } \\
\text { deviation }\end{array}$ & $\begin{array}{c}\text { Freedom } \\
\text { degrees }\end{array}$ & $\mathrm{t}$ \\
\hline \multirow{2}{*}{ Initial test } & Control group & 9 & 5,75 &, 28 & \multirow{2}{*}{21} & \multirow{2}{*}{$1,02 * *$} \\
\hline & Experiment group & 15 & 5,62 &, 28 & & \\
\hline \multirow{2}{*}{ Final test } & Control group & 9 & 6,66 & 52 & \multirow{2}{*}{21} & \multirow{2}{*}{$9,21 *$} \\
\hline & Experiment group & 15 & 8,34 &, 31 & & \\
\hline
\end{tabular}

According to Table 2, the average grade of the initial test, both the control group and experimental group, were close - 5.75 and 5.62. This shows that the assimilation level of acrobatic elements is approximately equal.

Precisely because the difference is very small, we wanted to see if by applying teaching strategies in the experimental group and traditional work in the control group, the average grade is changed.

Thus, it is seen from table that the results in final testing of the two groups are different, and the difference is quite large. The control group obtained an average 6.66 in final testing and experimental group received an average grading of 8.34 points.

The significance of the progress made by the experiment group of girls is given by significance threshold analysis, with a value of $p<.05$, indicating that the difference between the two groups is significant for the experiment.

We can say that teaching strategy in the experimental group had the desired effect, that this group has made greater progress in learning acrobatic elements, compared to the control group.

In the same control group was done a statistical analysis of the results of initial testing and final. The results were recorded in Table 3.

Table 3 - Statistical analysis of the initial and final test of the control group

\begin{tabular}{ccccccc}
\hline & Control group & $\begin{array}{c}\text { Number of } \\
\text { subjects }\end{array}$ & Average & Standard deviation & $\begin{array}{c}\text { Freedom } \\
\text { degrees }\end{array}$ & $\mathrm{t}$ \\
\hline \multirow{2}{*}{ Girls } & Initial test & 9 & 5,68 &, 29 & & \\
& Final test & 9 & 6,90 &, 33 & 8 & $31,11^{*}$ \\
\hline $\mathrm{p}<.05$ & & & & & &
\end{tabular}

According to the data reported in Table 3 we see that the average grade on the final test in the control group of girls progressing compared to initial testing.

Thus, within the initial testing, the average grade obtained by the girls in the control Group was 5.68. The result of final test, with an average grading of 6.90 , shows that by trained means, also the control group recorded a positive trend in learning acrobatic elements. 
Comparing the two results is noted that the control group of girls has progressed with $21.47 \%$ compared to initial testing.

We can appreciate from this perspective that female students have acquired the acrobatic elements through participation in physical education classes and practicing content traditionally.

This shows us the formative role of the educational process in the formation of specific skills.

To observe the effects of teaching strategy in the experimental group and that this group progressing to the final testing, we continued the statistical analysis and the results of pooled data and their interpretation are presented in Table 4.

Table 4 - Statistical analysis of the initial and final test of the experiment

\begin{tabular}{lcccccc}
\hline & Experiment group & $\begin{array}{c}\text { Number of } \\
\text { subjects }\end{array}$ & Average & Standard deviation & $\begin{array}{c}\text { Freedom } \\
\text { degrees }\end{array}$ & $\mathrm{t}$ \\
\hline \multirow{2}{*}{ Girls } & Initial test & 15 & 5,63 &, 25 & 14 & $57,13^{*}$ \\
& Final test & 15 & 8,36 &, 28 & & \\
\hline $\mathrm{p}<.05$ & & & & &
\end{tabular}

As shown, the average grading to final testing of the girls in the experimental group had a value of 8.36 . Compared to the average obtained at initial testing, which was 5.63, it appears that progress experiment group was $48.49 \%$, much higher than the control group progress. The fact that statistical indicator is $\mathrm{p}<05$ indicates that this progress is significant.

\section{Conclusions}

Results from the initial tests and the final recorded a significant progress both in the control and experiment group. It was observed in this experiment, by comparison, that the experimental group showed a higher improvement than the control group. Using teaching strategies led to a greater attractiveness of the lesson and a higher motor skills density. Means used in the experimental group proved effective, students recording a better scoring in the final testing.

Having increased mobility, students can easily own acrobatic elements and jumping. According to the progress of the experimental group students was noted that operating systems designed for this experiment were accessible.

The initial hypothesis was confirmed, which shows that the teaching strategies used in physical education lesson can be a sustainable alternative in learning acrobatic elements and jumping.

\section{References}

1. Bontaş I., Treaty of pedagogy, (pp. 24-26) Sixth edition revised and enlarged, Bic All Publishing, Bucharest, (2007).

2. Cârstea, Gh., Theory and methodology of physical education and sport, (pp. 98-99) An-Da Publishing, Bucharest, (2000).

3. Cerghit, I., Educational methods,(pp. 31) Fourth edition revised, Polirom Publishing, Iasi, (2006).

4. Nicola, I., Treaty of school pedagogy, Aramis Publishing, Bucharest, (2000).

5. Pîslaru, V., Educational technologies Guidelines, Litera Publishing, Bucharest, (1999).

6. Sloan, S., An investigation into the perceived level of personal subject knowledge and competence of a group of pre-service physical education teachers towards the teaching 
of secondary schoolgymnastics, European Physical Education Review, Vol.13, no.1, pp 57-80, London, Sage Publications Ltd., (2007).

7. Stan, L. et al., Guidelines for the design of activities teaching-learning-assessment, (pp. 62-63) Aramis Publishing, Bucharest, (2005). 